\title{
Comparison of corneal biomechanics after myopic small-incision lenticule extraction compared to LASIK: an ex vivo study
}

This article was published in the following Dove Press journal: Clinical Ophthalmology

\author{
Anastasios John \\ Kanellopoulos ${ }^{1,2}$ \\ 'Department of Ophthalmology, \\ Laservision Clinical and Research \\ Institute, Athens, Greece; \\ ${ }^{2}$ Department of Ophthalmology, \\ New York University Medical School, \\ New York, NY, USA
}

Purpose: To investigate ex vivo potentially different corneal biomechanical properties after small-incision lenticule extraction (SMILE) versus LASIK for myopic correction.

Methods: Thirty human donor corneas were subjected to either myopic SMILE or femtosecond laser-assisted LASIK. Donor corneas were assigned to six investigative groups: Group A, -3.00 D (diopters) SMILE; Group B, -8.00 D SMILE; Group C, -3.00 D LASIK; and Group D, -8.00 D LASIK. Additionally, two control groups were formed: Group E, SMILE and Group F, LASIK. All groups consisted of five corneas, randomly allocated. The corneas in the control groups were subjected to the corresponding femtosecond-laser lamellar cuts but not to tissue removal. Evaluation of biomechanical tensile strength was conducted by biaxial force application. Primary outcome measures were stress at $10 \%$ and $15 \%$ strain, and Young's modulus at $10 \%$ and $15 \%$ strain.

Results: In SMILE, the average relative difference $(\Delta)$ of the four outcome measures was $-34.46 \%$ for $-3.00 \mathrm{D}$ correction versus control Group E and $-49.34 \%$ for $-8.00 \mathrm{D}$ correction versus control Group E. In LASIK, average $\Delta$ was $-24.88 \%$ for -3.00 D correction versus control, and $-52.73 \%$ for $-8.00 \mathrm{D}$ correction versus control. All these differences were statistically significant; SMILE compared to LASIK for the same myopic correction appears to result in more biomechanical reduction for $-3.00 \mathrm{D}$ corrections by $-26 \%$, while a nonstatistically significant difference was noted in $-8.00 \mathrm{D}$ corrections.

Conclusion: Both SMILE and LASIK procedures do substantially alter corneal biomechanical properties, and the degree of tensile strength reduction is statistically significantly correlated to the extent of myopic correction. Additionally, SMILE procedure seems to result in more tensile strength reduction in lower myopic corrections compared to LASIK, and similar tensile strength reduction to LASIK in higher myopic corrections when compared to LASIK.

Keywords: SMILE, femto-second LASIK, myopic LASIK, corneal biomechanics, Young's modulus, corneal stress-strain, shear strength, tensile strength

\section{Introduction}

Small-incision lenticule extraction (SMILE) procedure ${ }^{1,2}$ is a new method of intrastromal keratomileusis that seems to be a viable alternative for refractive correction, since numerous recent studies validate its safety and efficacy, even when compared to LASIK procedure the current laser refractive procedure of choice to treat myopia.,4

SMILE is a new single femtosecond laser "flapless" procedure that involves the creation of an intrastromal lenticule between two photo disruption planes that is mechanically removed through a small corneal incision tunnel of 2-3 mm diameter typically created superotemporally. ${ }^{5}$ 
On the other hand, LASIK procedure involves two distinct steps: the creation of the flap (corresponding to a lamellar cut typically $110-140 \mu \mathrm{m}$ within the cornea) by either a mechanical microkeratome or a femtosecond laser (usually operating at 1,056 nm), ${ }^{6}$ followed by the refractive part, the ablative removal of stromal tissue from the exposed bed under the lifted flap using an excimer laser (usually operating at $193 \mathrm{~nm})^{7}$

The removal of corneal tissue by either procedure inevitably leads to reduction of corneal tensile strength. ${ }^{10,11}$ Both procedures alter corneal biomechanical properties that are thought to play an important role in the development of post-LASIK ectasia, but the nature of each procedure may produce different biomechanical effects. First, it is known that vertical cuts have more biomechanical impact than horizontal cuts. In SMILE significantly less anterior cornea is subjected to transverse separation, since side cut diameter is $2-3 \mathrm{~mm}\left(50^{\circ}\right)$ compared to LASIK where flap diameter is of $300^{\circ}$, that is, $360^{\circ}$ minus only the hinge. Additionally, it is also known that anterior stromal lamellae are stronger than posterior stromal lamellae, and the anterior $40 \%$ of the central corneal stroma constitutes the strongest region of the cornea, whereas the posterior $60 \%$ of the stroma is at least $50 \%$ weaker. In SMILE, since the anterior stroma remains uncut and the tissue is removed from deeper stromal layers than in LASIK, the strongest part of the stroma continues to contribute to the strength of the cornea postoperatively.

In this study, we attempted to comparatively evaluate the changes in corneal biomechanical properties ex vivo following either SMILE (Visumax Laser; Carl Zeiss Meditec AG, Jena, Germany) or Femtosecond LASIK (FS200 \& EX500 Lasers; Alcon Surgical, Fort Worth, TX, USA) for high or low myopic correction.

\section{Materials and methods}

This laboratory (ex vivo) study received approval by the Ethics Committee of Laservision.gr Clinical Research Eye Institute. Thirty human donor corneas were used in this study, which were obtained for research purposes from the Eye Bank for Sight Restoration Inc. (New York, NY, USA), an accredited member of the Eye Bank Association of America. The corneas were donated by 30 different organ donors (17 males and 13 females), whose mean age was $60.9 \pm 10.1$ years (range 46-78 years). The corneas were stored in OptiSol (Bausch \& Lomb, Rochester, NY, USA) solution and were maintained at $4^{\circ} \mathrm{C}$.

\section{Sample preparation}

The human donor corneas were randomly assigned to six investigative groups ( $\mathrm{n}=5$ each) which were subjected to the following myopic simulated treatments: Group A, $-3.00 \mathrm{D}$ SMILE; Group B, -8.00 D SMILE; Group C, -3.00 D LASIK; and Group D, -8.00 D LASIK. Two control groups were formed (also $\mathrm{n}=5$ each), one for each procedure, Group E, control group for SMILE, and Group F, control group for LASIK. The corneas in these control groups were subjected to the corresponding femtosecond laser lamellar cut at $140 \mu \mathrm{m}$ depth and "smile" side cut for SMILE cases, and to the corresponding $110 \mu \mathrm{m}$ LASIK flap cut in LASIK cases, but not to any tissue removal.

During the procedures, the corneas were mounted on artificial anterior chamber (Baron; Katena Products, Inc., Denville, NJ, USA). In either procedure, suction was manually activated, and centration was manually achieved during the femtosecond laser step.

SMILE procedures were performed using the $500 \mathrm{kHz}$ VisuMax femtosecond laser (Carl Zeiss Meditec AG). Software version 1.16 was used to plan the procedures, choosing an optical zone of $6.50 \mathrm{~mm}$, a cap diameter of $7.50 \mathrm{~mm}$ at $140 \mu \mathrm{m}$ depths, and a lenticule cut diameter of $5.32 \mathrm{~mm}$. For the $-3.00 \mathrm{D}$ corrections (Group A), the maximum lenticule thickness was $64 \mu \mathrm{m}$ (minimum $15 \mu \mathrm{m}$ ). For the $-8.00 \mathrm{D}$ corrections (Group B), the maximum lenticule thickness was $136 \mu \mathrm{m}$ (minimum $15 \mu \mathrm{m}$ ). The two lenticule interfaces (upper and lower) were manually separated through a $2 \mathrm{~mm}$ lateral "tunnel" incision in an upper/lower order. The lenticule was then extracted using microforceps via this incision. The corneas, in the control group for SMILE (Group E), were subjected to the two lamellar cuts and manual separations corresponding to the $-3.00 \mathrm{D}$ correction, but the lenticule was not removed.

The LASIK procedure was performed using the WaveLight Refractive Suite ${ }^{\mathrm{TM}}$, namely: 1) the FS200 femtosecond laser (Alcon Surgical) for the creation of a $110 \mu \mathrm{m}$ thick, $8.0 \mathrm{~mm}$ diameter corneal flap, followed by 2) the WaveLight EX-500 excimer laser (Alcon), employing the "Wavefront Optimized" procedure for the ablative tissue removal. Optical zone diameter was $6.50 \mathrm{~mm}$. For the $-3.00 \mathrm{D}$ corrections, the maximum ablation depth was $45.51 \mu \mathrm{m}$, while for the $-8.00 \mathrm{D}$ corrections it was $114.71 \mu \mathrm{m}$. The flaps were then repositioned in place. The corneas in the control for LASIK (group-F) were subjected to flap creation, which was subsequently lifted and repositioned without any ablative excimer laser tissue removal. 
Following the operations, the cornea specimens were stored back into OptiSol and maintained at $4^{\circ} \mathrm{C}$ until testing. To obtain central corneal thickness, contact ultrasound pachymetry was employed prior to the following tensile strength testing (PachPen; Accutome Inc., Malvern, PA, USA). ${ }^{8}$ All cornea specimens were then trephined by a $9.50 \mathrm{~mm}$ round punch at their center section.

\section{Tensile strength testing}

The Biotester 5000 System (CellScale Biomaterials Testing, Waterloo, ON, Canada) was used to provide biaxial load cell-based in-plane tensile tests. The specimens were fixed (randomly orientated) on a $4 \times 5$-tine rake arrangement (Figure 1) at their center $3.5 \times 3.5 \mathrm{~mm}$ square section. The tines were of $250 \mu \mathrm{m}$ diameter and spaced apart by $0.7 \mathrm{~mm}$. Shear rate was fixed to $4.16 \mu \mathrm{m} / \mathrm{s}$. The specimens on the fixation unit were submerged in an isotonic saline bath ( $9 \mathrm{mg} / \mathrm{mL}$ sodium chloride solution; B. Braun Melsungen AG, Melsungen, Germany), temperature controlled at $37^{\circ} \mathrm{C}$ for 5 minutes before testing to allow for temperature stabilization, as well as during testing to eliminate any temperaturerelated variability. Testing was performed until the first sign of slippage, indicated by an abrupt change in the force-strain curve, displayed real-time in the system monitor.
The following data time (s), $x$ and $y$ size $(\mu \mathrm{m}) x$ - and $y$-axis displacement $(\mu \mathrm{m}), x$ - and $y$-applied force $(\mathrm{mN})$, and $x$ and $y$ strain (unitless) were recorded every second. An integrated CCD camera, capturing still images at a $1,280 \times 960$ pixel resolution, facilitated the precise $x$ - and $y$-displacement measurement. Data were processed by custom software (LabJoy v. 9.05; CellScale Biomaterials Testing). ${ }^{9}$

For Groups C, D, and F corneas (LASIK treated), the flap remained positioned on the stromal bed to maintain similar thickness and thus reduce comparison bias with the SMILEtreated corneas (Groups A, B, and E).

\section{Data evaluation}

For data evaluation, the following definitions have been adopted: strain, the unitless relative elongation $(\Delta x / l$ or $\Delta y / l)$, where $(l)$ is the initial dimension of $3.5 \mathrm{~mm}$, expressed as percentage and stress, a pressure metric, as the applied force $F$ divided by the cross-section $(A)$ of the corneal specimen test area $(F / A)\left(F / A\right.$, units $=\mathrm{mN} / \mathrm{mm}^{2}=\mathrm{kPa}=10^{3} \mathrm{~Pa}$; $\mathrm{MPa}=10^{6} \mathrm{~Pa}$, where $\mathrm{Pa}$ stands for Pascal, SI unit for pressure). Cross-section of the test area $(A)$ was defined by $3.5 \mathrm{~mm} x$ - (or $y$-, respectively) width multiplied by the measured central corneal thickness. Stress at $10 \%$ and $15 \%$ strain was recorded.

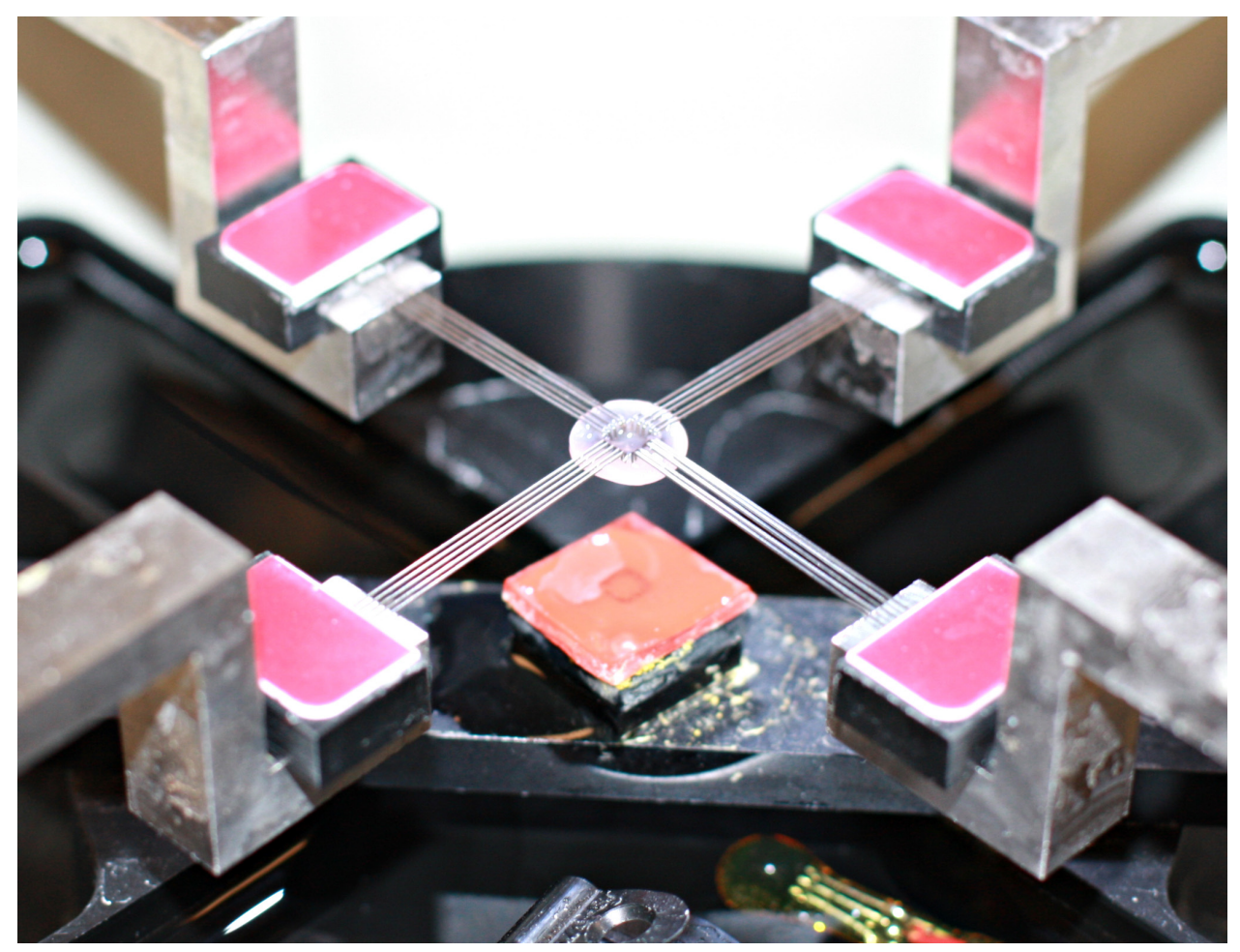

Figure I Fitting of the corneal specimen on the BioTester device rake battery just prior to testing. 
Young's modulus (also known as stress/strain ratio) is associated with tissue resistance to tensile strains. It is defined as the ratio of stress to strain applied to the tissue, and is also consequently expressed in units of pressure $\left(\mathrm{MPa}=10^{6} \mathrm{~Pa}\right)$. To calculate Young's modulus, two-dimensional graphs were constructed by plotting stress in the vertical axis versus strain in the horizontal. Linear regression fitting using the SPSS software version 21.0 (IBM Corporation, Armonk, NY, USA) was applied on the linear section of the loading curve to calculate, by means of the slope function (gradient), the stress-strain ratio. Young shear modulus $E$ was calculated as the gradient at the vicinity of $10 \%$ and $20 \%$ strain on the stress-strain graph.

Specifically, for all 60 data sets ( 6 groups $\times 5$ specimens each $\times 2$ data sets per specimen, one for the $x$ - and one for the $y$-dimension):

1. The values for stress at $10 \%$ and $15 \%$ strain were recorded.

2. The values for Young's modulus were calculated at $10 \%$ and $15 \%$ strain. For the $10 \%$ calculation, the data range was selected to correspond to strain extending from $7 \%$ to $13 \%$, and for the $15 \%$ calculation, to strain extending from $12 \%$ to $18 \%$.

\section{Results}

Donor data of the tissue used, provided by the Eye Bank, were recorded and analyzed: mean donor age at the time of cornea harvest was $59.4 \pm 12.8$ years for Group A, $62.5 \pm 6.9$ years for Group B, 58.5 \pm 14.2 years for Group C, $64.2 \pm 5.8$ years for Group D, $54.7 \pm 12.1$ years for Group E, and 63.9 \pm 8.5 years for Group F. No statistically significant difference between the groups was noted.

Mean central corneal thickness as measured prior to the tensile strength testing was $663.3 \pm 32.7 \mu \mathrm{m}$ in Group A, $549 \pm 26.0 \mu \mathrm{m}$ in Group B, 674.7 $\pm 51.5 \mu \mathrm{m}$ in Group C, $553.9 \pm 25.9 \mu \mathrm{m}$ in Group D, $699.4 \pm 33.9 \mu \mathrm{m}$ in Group E, and $692.4 \pm 21.7 \mu \mathrm{m}$ in Group F. The distinct data sets collected during the tensile measurements on each cornea specimen were on average $230 \pm 30$ (range: 137-255). Average displacement was $983.0 \pm 76.1 \mu \mathrm{m}$ (range: $795-1,062$ ), mean maximum applied force was 4,266.0 $\pm 694.3 \mathrm{mN}$ (range: $3,428-5,740$ ), and maximum strain was $24.6 \% \pm 1.7 \%$ (range: $20.3-26.3$ ).

Examples of stress-strain curves are shown in Figure 2. For the calculation of Young's modulus, 65 distinct data pairs (vertical axis: stress and horizontal axis: strain) contributed to each slope function derivation. The average coefficient of determination $\left(R^{2}\right)$ of the trend lines was $0.994 \pm 0.004$ (range: 0.987-0.998).
Table 1 provides stress and Young's modulus results from all six groups (Figure 3), comparatively analyzed in Table 2. Within the same procedure (eg, within SMILE or LASIK), the corneas that received the larger myopic correction $(-8.00 \mathrm{D})$ displayed more tensile strength reduction compared to the smaller myopic correction $(-3.00 \mathrm{D})$ by all metrics. More precisely, within SMILE procedure, the average tensile strength reduction $\Delta$ (numeric average of the four metrics: Young's modulus@10\%, Young's modulus @ 15\%, stress@10\%, and stress@15\%, Table 2) for the -3.00 D correction (Group A) was $-34.46 \%$ when compared to the SMILE control (Group E), and for the -8.00 D correction (Group B) it was $-49.34 \%$ also when compared to SMILE control (Group E). Compared to the $-3.00 \mathrm{D}$ correction (Group A), the -8.00 SMILE correction (Group B) had on average $-22.70 \%$ reduced corneal biomechanical metrics. All these differences were statistically significant.

Within LASIK, the average $\Delta$ of the $-3.00 \mathrm{D}$ correction (Group C) was $-24.88 \%$, when compared to the LASIK control (Group F) and $-52.73 \%$ for the -8.00 D correction (Group D), again statistically significant. Compared to the -3.00 D correction (Group C), the -8.00 D LASIK correction (Group D) had on average $-37.07 \%$ reduced corneal biomechanical metrics.

\section{Discussion}

Both SMILE and LASIK procedures have performed well in studies in all measures of safety, efficacy, and predictability for myopia correction..$^{10}$ Despite their common objective, there are fundamental operating differences between these two procedures. SMILE, a relatively newer and evolving procedure, has been so far employed for the correction of myopia and/or myopic astigmatism in the range of -3 to -10 Ds, ${ }^{11}$ while LASIK has a broader treatment range, including higher amounts of myopia, as well as the correction of hyperopic refractive errors. ${ }^{12,13}$ In addition, LASIK may be applied for customized treatments where centration can be actively controlled and cyclorotation compensated and where wavefront and/or topographic data can be incorporated in the tissue pattern planned for removal, ${ }^{14}$ and potentially has the benefit of vast surgical and research experience.

The potential obvious advantages of SMILE over LASIK apart from biomechanics include reduced dependence on environmental factors that may influence excimer stromal ablation, such as laser fluence variability and stromal hydration, reduced possibility for operating room airborne foreign-body interface contamination, and potentially reduced postoperative dry-eye symptoms. ${ }^{15}$ In terms of 

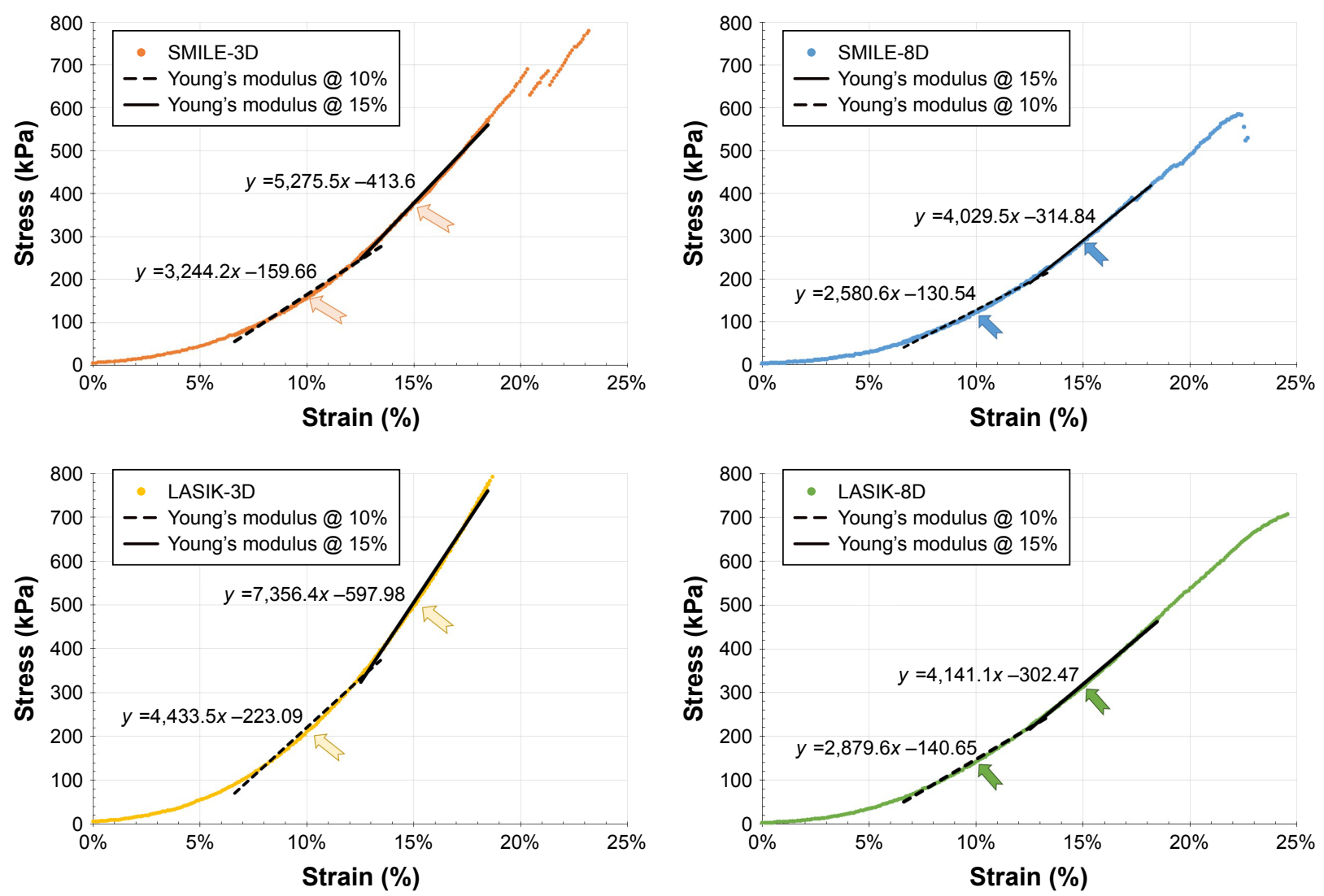

Figure 2 Young's modulus $E$ linear regression fitting performed on stress-strain curves.

Notes: Data illustrate stress (shear force $\div$ cross-section, expressed in $\mathrm{kPa}$ ) versus relative displacement (strain, reported as \%). From left to right, top to bottom, Group $\mathrm{A}$ (SMILE-3D), Group B (SMILE-8D), Group C (LASIK-3D), and Group D (LASIK-8D). Young's modulus corresponds to the slope, which is indicated by the numeric factor preceding variable $x$ in each trend-line function per group, expressed in $\mathrm{kPa}$ and converted to $\mathrm{MPa}$ in the data listed in Table $\mathrm{I}$.

Abbreviation: SMILE, small-incision lenticule extraction.

Table I Comparative tensile measurements between the six groups

\begin{tabular}{|c|c|c|c|c|}
\hline Metric & $\begin{array}{l}\text { Young's } \\
\text { modulus @ } \\
\text { I0\% (MPa) }\end{array}$ & $\begin{array}{l}\text { Young's } \\
\text { modulus @ } \\
\text { I5\% (MPa) }\end{array}$ & $\begin{array}{l}\text { Stress @ } \\
\text { I0\% (kPa) }\end{array}$ & $\begin{array}{l}\text { Stress @ } \\
\text { I5\% (kPa) }\end{array}$ \\
\hline \multicolumn{5}{|c|}{ Group E SMILE control } \\
\hline Mean & 5.09 & 8.17 & 248 & 580 \\
\hline SD & \pm 0.78 & \pm 0.92 & \pm 54 & \pm 75 \\
\hline \multicolumn{5}{|c|}{ Group A SMILE-3D } \\
\hline Mean & 3.24 & 5.28 & 160 & 376 \\
\hline SD & \pm 0.85 & \pm 1.06 & \pm 66 & \pm 98 \\
\hline \multicolumn{5}{|c|}{ Group B SMILE-8D } \\
\hline Mean & 2.58 & 4.03 & 123 & 287 \\
\hline SD & \pm 0.55 & \pm 0.81 & \pm 35 & \pm 72 \\
\hline \multicolumn{5}{|c|}{ Group F LASIK control } \\
\hline Mean & 5.63 & 9.34 & 266 & 632 \\
\hline SD & \pm 0.65 & \pm 0.91 & \pm 68 & \pm 92 \\
\hline \multicolumn{5}{|c|}{ Group C LASIK-3D } \\
\hline Mean & 4.43 & 7.36 & 210 & 498 \\
\hline SD & $\pm 0.8 \mathrm{I}$ & \pm 1.16 & \pm 77 & \pm 108 \\
\hline \multicolumn{5}{|c|}{ Group D LASIK-8D } \\
\hline Mean & 2.88 & 4.14 & 142 & 313 \\
\hline $\mathrm{SD}$ & \pm 0.59 & \pm 0.48 & \pm 47 & \pm 69 \\
\hline
\end{tabular}

Note: Data represent mean and standard deviation between all corneas within each group.

Abbreviations: SD, standard deviation; SMILE, small-incision lenticule extraction. corneal sensation and dry eye outcomes, some studies, as well as our own unreported to-date experience, have shown equivalence - if not superiority - of SMILE over LASIK. ${ }^{16-18}$

This study focuses mainly on the investigation of the degree of reduction in corneal biomechanical strength as a result of either SMILE or LASIK. Its importance derives from the fact that significant loss of corneal strength in large myopic corrections may lead to refractive regression, ${ }^{19}$ and/or possibly iatrogenic ectasia. ${ }^{20-22}$ In LASIK, barring the ablated tissue significance, the flap creation itself further contributes to reduction of corneal strength since, despite it still being attached to the "processed" stroma, it may no more conduce to the biomechanical strength of the underlying stroma. ${ }^{11,12}$ In SMILE, in theory, the cornea should be less affected compared to any given LASIK or photorefractive keratectomy (PRK) procedure, as most of the anterior stromal lamellae remain intact above the cavity created by the extracted lenticule, ${ }^{10,13}$ keeping in mind the depth dependence of transverse shear modulus of the cornea (stronger at the anterior third). ${ }^{23-25}$ 

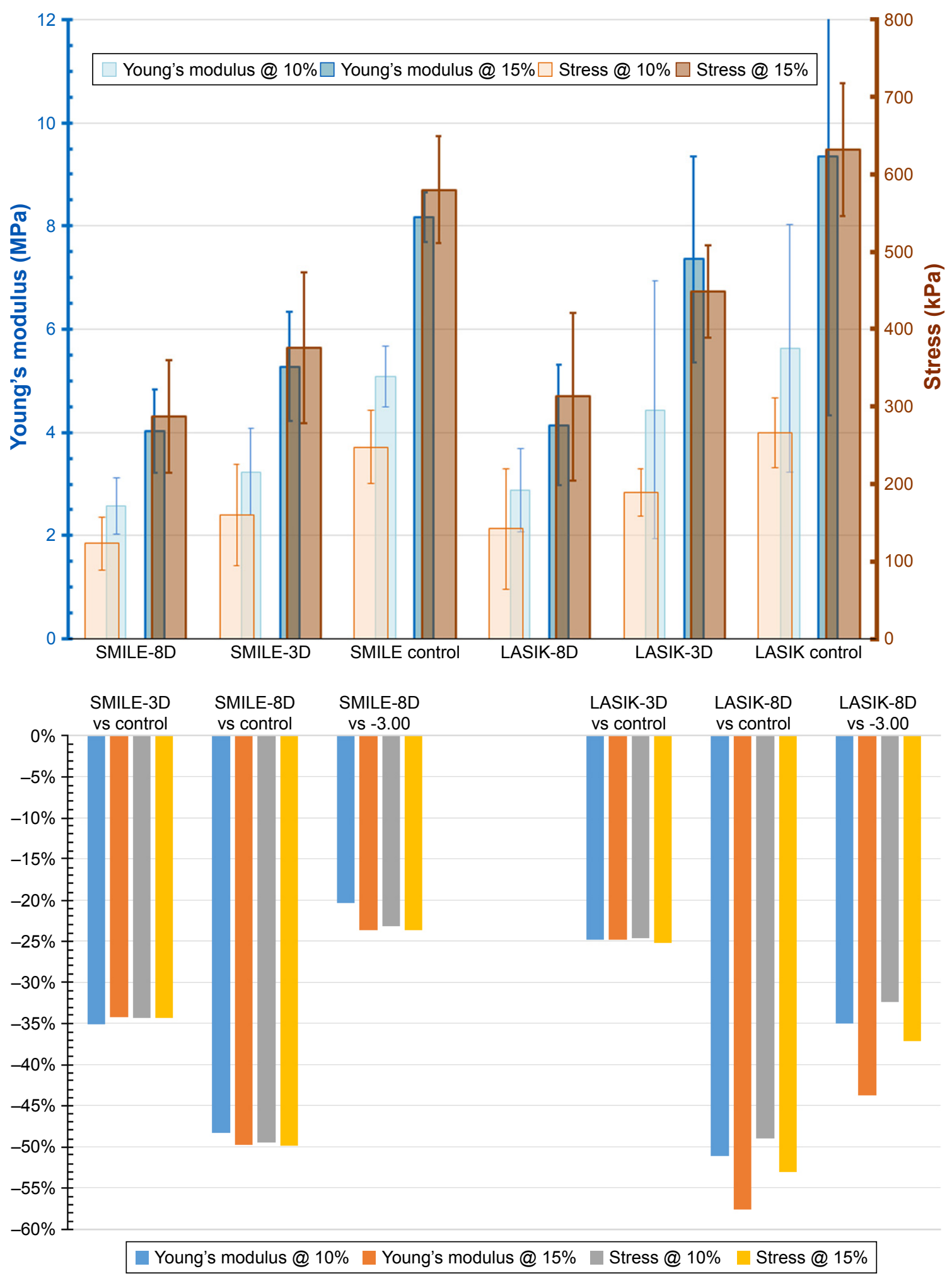

Figure 3 Summary of biomechanical tensile test differential results per group studied.

Note: Young's modulus (units $\mathrm{MPa}$ ) and stress results (units $\mathrm{kPa}$ ) calculated at $10 \%$ and $15 \%$ strain.

Abbreviation: SMILE, small-incision lenticule extraction.

These effects have been described or hypothesized, ${ }^{13,26}$ but to the best of our knowledge, no experimental or clinical evidence on this aspect has been presented in the peerreviewed literature.
In this study, we conducted a human ex vivo comparative investigation of the potential in-plane tensile strength reduction in corneas subjected to either SMILE or femtosecond laser-assisted LASIK as in vivo biomechanical 
Table 2 Comparative analysis of tensile results

\begin{tabular}{|c|c|c|c|c|c|}
\hline & $\begin{array}{l}\text { Young's modulus } \\
@ 10 \%(\mathrm{MPa})\end{array}$ & $\begin{array}{l}\text { Young's modulus } \\
\text { @ I5\% (MPa) }\end{array}$ & $\begin{array}{l}\text { Stress @ } \\
10 \%(\mathrm{kPa})\end{array}$ & $\begin{array}{l}\text { Stress@ } \\
15 \%(\mathrm{kPa})\end{array}$ & Average $\Delta$ \\
\hline \multicolumn{6}{|l|}{$\Delta$ within procedure } \\
\hline SMILE-3D vs control & $-36.3 \%$ & $-35.4 \%$ & $-35.5 \%$ & $-35.2 \%$ & $-35.6 \%$ \\
\hline SMILE-8D vs control & $-49.3 \%$ & $-50.7 \%$ & $-50.4 \%$ & $-50.5 \%$ & $-50.2 \%$ \\
\hline SMILE-8D vs -3.00 & $-20.4 \%$ & $-23.6 \%$ & $-23.1 \%$ & $-23.7 \%$ & $-22.7 \%$ \\
\hline LASIK-3D vs control & $-21.3 \%$ & $-21.2 \%$ & $-21.1 \%$ & $-21.2 \%$ & $-21.2 \%$ \\
\hline LASIK-8D vs control & $-48.9 \%$ & $-55.7 \%$ & $-46.6 \%$ & $-50.5 \%$ & $-50.4 \%$ \\
\hline LASIK-8D vs -3.00 & $-35.1 \%$ & $-43.7 \%$ & $-32.4 \%$ & $-37.1 \%$ & $-37.1 \%$ \\
\hline \multicolumn{6}{|c|}{$\Delta$ between same dioptric correction } \\
\hline SMILE-3D vs LASIK-3.00 & $-27 \%$ & $-28 \%$ & $-24 \%$ & $-24 \%$ & $25.9 \%$ \\
\hline SMILE-8D vs LASIK-8.00 & $-10 \%(*)$ & $-3 \%(*)$ & $-13 \%(*)$ & $-8 \%(*)$ & $-8.7 \%(*)$ \\
\hline
\end{tabular}

Notes: $\Delta$ : relative (\%) difference between metrics; *difference was not statistically significant $(P>0.05)$. Average $\Delta$ is the numeric average of the four metrics (Young's modulus@ @ 15\%, stress@ @ 10\%, and stress@ 15\%).

Abbreviation: SMILE, small-incision lenticule extraction.

measurements, in our experience, have shown low specificity and sensitivity. To the best of our knowledge, this is the first experimental investigation of this issue.

All the samples used, as well as the procedures implemented, were as closely matched as possible. The corneal samples had no statistically significant age, gender, or race difference; the operations were designed in a way they would reflect current clinical standards in our practice: the upper lamellar dissection in SMILE was created at $140 \mu \mathrm{m}$, and the femtosecond LASIK flap was created at $110 \mu \mathrm{m}$, exactly as in our clinical practice. To evaluate the effect on corneal biomechanical properties, we used biaxial stress-strain measurements, ${ }^{27,28}$ which may be superior to corneal strip extensiometry used in earlier experiments considering the nonuniform topographic distribution of the corneal strength profile. ${ }^{29,30}$ Thus, the orientation of the cornea specimens during the tensile measurements was intentionally random, to exactly address the fact that the in-plane biomechanical properties may naturally vary along different corneal meridians because of the known anisotropic differences of corneal collagen. ${ }^{31-33}$

The data in this study suggest that SMILE and LASIK appear to result in statistically similar tensile strength reduction for higher myopic corrections $(-8.00 \mathrm{D})$; however, LASIK appears to result in less corneal strength reduction in smaller myopic correction $(-3.00 \mathrm{D})$.

These admittedly unexpected results may be attributed to a number of significant differences between the two procedures. SMILE results in more tissue removal, due to the minimum additional $15 \mu \mathrm{m}$ tissue dissected, independent of the amount of myopia corrected. In the -3.00 D SMILE corrections, the maximum lenticule thickness was $64 \mu \mathrm{m}$ and in the $-8.00 \mathrm{D}$ corrections, $136 \mu \mathrm{m}$. Additionally, the tissue removal starts "deeper" at $140 \mu \mathrm{m}$ in comparison to LASIK ablation starting at $110 \mu \mathrm{m}$. On the other hand, in LASIK, in the $-3.00 \mathrm{D}$ corrections, the maximum ablation depth was $45.51 \mu \mathrm{m}$, and in the $-8.00 \mathrm{D}$ corrections, $114.71 \mu \mathrm{m}$. These differences exist despite the same $6.50 \mathrm{~mm}$ optical zone for all procedures performed. These data correspond to an average of $19.5 \mu \mathrm{m}$ per diopter of removed tissue in SMILE, compared to an average of $14.74 \mu \mathrm{m}$ per diopter of ablated tissue in LASIK.

Another possible factor contributing to differences in tissue loss and resulting tensile strength reduction changes is the possible uncertainty of the depth of the lamellar cut produced by the femtosecond laser. The precision of the achieved depth (thickness) of femtosecond-created LASIK flap has been reported in the peer-review literature, ${ }^{34}$ to be in the vicinity of \pm 3 to $\pm 5 \mu \mathrm{m} .{ }^{35}$ The variability in the maximum ablated tissue by the excimer laser also constitutes an independent factor. ${ }^{36}$

In SMILE procedure, there are two such femtosecond laser lamellar dissections, the upper and the lower, separated by a minimum $15 \mu \mathrm{m}$ plus the necessary, nomogramrecommended maximum lenticule thickness. For example, the upper interface may be $140 \mu \mathrm{m}$ within the cornea and the lower interface up to $280 \mu \mathrm{m}$ within the cornea $(140+136 \mu \mathrm{m}$, in the example of $-8.00 \mathrm{D}$ ). This factor may introduce a large deviation between the programmed and achieved thickness of the removed tissue, for two reasons: first, the need for two lamellar dissections introduces a possible deviation of the maximum lenticule thickness, which may cumulatively result in the order of $\pm 10 \mu \mathrm{m}$. Second, the depth for the very deep lamellar cut may not be as precise as for a typically anterior flap cut. These issues, of course, deserve a thorough investigation, which is outside the scope of this work.

Limitations of our study may include limited statistical power due to the sample size as well as acceptance of a basic 
assumption that the in-plane tensile strength testing (eg, along the $x$ and $y$ dimensions) corresponds to in vivo biomechanical behavior of the cornea. ${ }^{37}$ A laminar tissue such as the corneal stroma could potentially have very high tensile strength due to the contribution of the collagen fibers (fibrils) and yet be very weak in shear strength due to little interweaving. However, testing the corneal samples of a thickness in the order of $500 \mu \mathrm{m}(0.5 \mathrm{~mm})$ cross-section with a shearing approach was not possible using the technique employed in this study and would require torsional rheometry techniques. ${ }^{30}$ Additional studies with differentiation of myopic correction applied and depth of lenticule may be warranted to validate and further investigate the findings of this preliminary study. Evaluation of transverse shear biomechanical strength aspect may also contribute to this issue.

\section{Conclusion}

According to our study, both SMILE and LASIK procedures do substantially alter corneal biomechanical properties, and the degree of tensile strength reduction is statistically significantly correlated to the extent of myopic correction. Additionally, SMILE procedure seems to result in more tensile strength reduction in lower myopic corrections and similar tensile strength reduction in higher myopic corrections when compared to LASIK, ex vivo, a finding that could be partly attributed to differences of tissue loss existing between the two techniques.

\section{Disclosure}

The author holds consultant/advisory positions at Alcon/ WaveLight, Allergan, Avedro, i-Optics, Keramed, Zeiss, and ISP Surgical. The author reports no other conflicts of interest in this work.

\section{References}

1. Sekundo W, Kunert KS, Blum M. Small incision corneal refractive surgery using the small incision lenticule extraction (SMILE) procedure for the correction of myopia and myopic astigmatism: results of a 6 month prospective study. Br J Ophthalmol. 2011;95(3): 335-339.

2. Hjortdal JØ, Vestergaard AH, Ivarsen A, Ragunathan S, Asp S. Predictors for the outcome of small-incision lenticule extraction for Myopia. $J$ Refract Surg. 2012;28(12):865-871.

3. Shortt AJ, Allan BD, Evans JR. Laser-assisted in-situ keratomileusis (LASIK) versus photorefractive keratectomy (PRK) for myopia. Cochrane Database Syst Rev. 2013;(1):CD005135.

4. Kanellopoulos AJ, Asimellis G. Refractive and keratometric stability in high myopic LASIK with high-frequency femtosecond and excimer lasers. J Refract Surg. 2013;29(12):832-837.

5. Reinstein DZ, Archer TJ, Gobbe M. Small incision lenticule extraction (SMILE) history, fundamentals of a new refractive surgery technique and clinical outcomes. Eye Vis. 2014;1:3.
6. Kanellopoulos AJ, Asimellis G. Three-dimensional LASIK flap thickness variability: topographic central, paracentral and peripheral assessment, in flaps created by a mechanical microkeratome (M2) and two different femtosecond lasers (FS60 and FS200). Clin Ophthalmol. 2013;7:675-683.

7. Kanellopoulos AJ, Asimellis G. Long-term bladeless LASIK outcomes with the FS200 femtosecond and EX500 excimer laser workstation: the refractive suite. Clin Ophthalmol. 2013;7:261-269.

8. Lin F, Xu Y, Yang Y. Comparison of the visual results after SMILE and femtosecond laser-assisted LASIK for myopia. J Refract Surg. 2014;30(4):248-254.

9. Ganesh S, Gupta R. Comparison of visual and refractive outcomes following femtosecond laser-assisted LASIK with smile in patients with myopia or myopic astigmatism. J Refract Surg. 2014;30(9): 590-596.

10. Peyman M, Tai LY, Khaw KW, Ng CM, Win MM, Subrayan V. Accutome PachPen handheld ultrasonic pachymeter: intraobserver repeatability and interobserver reproducibility by personnel of different training grades. Int Ophthalmol. 2015;35(5):651-655.

11. Søndergaard AP, Ivarsen A, Hjortdal J. Corneal resistance to shear force after UVA-riboflavin cross-linking. Invest Ophthalmol Vis Sci. 2013;54(7):5059-5069.

12. Kanellopoulos AJ, Conway J, Pe LH. LASIK for hyperopia with the WaveLight excimer laser. J Refract Surg. 2006;22(1):43-47.

13. Kanellopoulos AJ, Kahn J. Topography-guided hyperopic LASIK with and without high irradiance collagen cross-linking: initial comparative clinical findings in a contralateral eye study of 34 consecutive patients. $J$ Refract Surg. 2012;28(11 Suppl):S837-S840.

14. Kanellopoulos AJ. Topography-guided hyperopic and hyperopic astigmatism femtosecond laser-assisted LASIK: long-term experience with the $400 \mathrm{~Hz}$ eye-Q excimer platform. Clin Ophthalmol. 2012;6: 895-901.

15. Moshirfar M, McCaughey MV, Reinstein DZ, Shah R, SantiagoCaban L, Fenzl CR. Small-incision lenticule extraction. J Cataract Refract Surg. 2015;41(3):652-665.

16. Denoyer A, Landman E, Trinh L, Faure JF, Auclin F, Baudouin C. Dry eye disease after refractive surgery: comparative outcomes of small incision lenticule extraction versus LASIK. Ophthalmology. 2015; 122(4):669-676.

17. Demirok A, Ozgurhan EB, Agca A, et al. Corneal sensation after corneal refractive surgery with small incision lenticule extraction. Optom Vis Sci. 2013;90(10):1040-1047.

18. Vestergaard AH, Grønbech KT, Grauslund J, Ivarsen AR, Hjortdal JØ. Subbasal nerve morphology, corneal sensation, and tear film evaluation after refractive femtosecond laser lenticule extraction. Graefes Arch Clin Exp Ophthalmol. 2013;251(11):2591-2600.

19. Magallanes R, Shah S, Zadok D, et al. Stability after laser in situ keratomileusis in moderately and extremely myopic eyes. $J$ Cataract Refract Surg. 2001;27(7):1007-1012.

20. Leccisotti A. Corneal ectasia after photorefractive keratectomy. Graefes Arch Clin Exp Ophthalmol. 2007;245:869-875.

21. Binder PS. Analysis of ectasia after laser in situ keratomileusis: risk factors. J Cataract Refract Surg. 2007;33(9):1530-1538.

22. Randleman JB. Post-laser in-situ keratomileusis ectasia: current understanding and future directions. Curr Opin Ophthalmol. 2006;17(4): 406-412.

23. Petsche SJ, Chernyak D, Martiz J, Levenston ME, Pinsky PM. Depthdependent transverse shear properties of the human corneal stroma. Invest Ophthalmol Vis Sci. 2012;53(2):873-880.

24. Dias J, Diakonis VF, Kankariya VP, Yoo SH, Ziebarth NM. Anterior and posterior corneal stroma elasticity after corneal collagen crosslinking treatment. Exp Eye Res. 2013;116:58-62.

25. Randleman JB, Dawson DG, Grossniklaus HE, McCarey BE, Edelhauser HF. Depth-dependent cohesive tensile strength in human donor corneas: implications for refractive surgery. $J$ Refract Surg. 2008;24(1):S85-S89. 
26. Sinha Roy A, Dupps WJ Jr, Roberts CJ. Comparison of biomechanical effects of small-incision lenticule extraction and laser in situ keratomileusis: finite-element analysis. J Cataract Refract Surg. 2014; 40(6):971-980.

27. Kanellopoulos AJ, Kontos MA, Chen S, Asimellis G. Corneal collagen cross-linking combined with simulation of femtosecond laser-assisted refractive lens extraction: an ex vivo biomechanical effect evaluation. Cornea. 2015;34(5):550-556.

28. Kanellopoulos AJ, Asimellis G, Salvador-Culla B, Chodosh J, Ciolino JB. High-irradiance CXL combined with myopic LASIK: flap and residual stroma biomechanical properties studied ex-vivo. $\mathrm{Br} J$ Ophthalmol. 2015;99(6):870-874.

29. Elsheikh A, Anderson K. Comparative study of corneal strip extensometry and inflation tests. J R Soc Interface. 2005;2(3):177-185.

30. Sánchez P, Moutsouris K, Pandolfi A. Biomechanical and optical behavior of human corneas before and after photorefractive keratectomy. J Cataract Refract Surg. 2014;40(6):905-917.

31. Smolek MK. Interlamellar cohesive strength in the vertical meridian of human eye bank corneas. Invest Ophthalmol Vis Sci. 1993;34(10): 2962-2969.
32. Abahussin M, Hayes S, Knox Cartwright NE, et al. 3D collagen orientation study of the human cornea using X-ray diffraction and femtosecond laser technology. Invest Ophthalmol Vis Sci. 2009;50(11): 5159-5164.

33. Radner W, Mallinger R. Interlacing of collagen lamellae in the midstroma in the human cornea. Cornea. 2002;21(6):598-601.

34. Kanellopoulos AJ, Asimellis G. FS200 femtosecond laser LASIK flap digital analysis parameter evaluation: comparing two different types of patient interface applanation cones. Clin Ophthalmol. 2013;7: 1103-1108.

35. Zheng Y, Zhou Y, Zhang J, Liu Q, Zhai C, Wang Y. Comparison of laser in situ keratomileusis flaps created by 2 femtosecond lasers. Cornea. 2015;34(3):328-333.

36. Kanellopoulos AJ, Georgiadou S, Asimellis G. Objective evaluation of planned versus achieved stromal thickness reduction in myopic femtosecond laser-assisted LASIK. J Refract Surg. 2015;31(9):628-632.

37. Hatami-Marbini H. Viscoelastic shear properties of the corneal stroma. J Biomech. 2014;47(3):723-728.
Clinical Ophthalmology

\section{Publish your work in this journal}

Clinical Ophthalmology is an international, peer-reviewed journal covering all subspecialties within ophthalmology. Key topics include: Optometry; Visual science; Pharmacology and drug therapy in eye diseases; Basic Sciences; Primary and Secondary eye care; Patien Safety and Quality of Care Improvements. This journal is indexed on

Submit your manuscript here: http://www.dovepress.com/clinical-ophthalmology-journal

\section{Dovepress}

PubMed Central and CAS, and is the official journal of The Society of Clinical Ophthalmology (SCO). The manuscript management system is completely online and includes a very quick and fair peer-review system, which is all easy to use. Visit http://www.dovepress.com/ testimonials.php to read real quotes from published authors. 